\title{
Free Radical-Dependent Dysfunction of Small-for-Size Rat Liver Grafts: Prevention by Plant Polyphenols
}

\author{
ZHI ZHONG,* HENRY D. CONNOR, ${ }^{\ddagger}$ MATTIAS FROH, ${ }^{\S}$ HARTWIG BUNZENDAHL, " HENRIK LIND,* \\ MARK LEHNERT,* RONALD P. MASON, ${ }^{*}$ RONALD G. THURMAN $\dagger, \$$ and JOHN J. LEMASTERS ${ }^{\top}$ \\ *Department of Cell and Developmental Biology, University of North Carolina, Chapel Hill, North Carolina; ${ }^{\circ}$ Laboratory of Pharmacology and

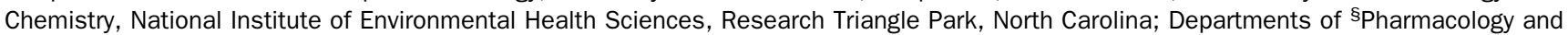 \\ "Surgery, University of North Carolina, Chapel Hill, North Carolina
}

Background \& Aims: The mechanisms by which smallfor-size liver grafts decrease survival remain unclear. This study investigated the role of free radicals in injury to small-for-size grafts. Methods: Rat liver explants were reduced in size ex vivo and transplanted into recipients of the same or greater body weight, resulting in a graft weight and standard liver weight of approximately $50 \%$ and $25 \%$, respectively. A polyphenol extract from Camellia sinenesis $(20 \mu \mathrm{g} / \mathrm{mL})$ or an equivalent concentration of epicatechin was added to the storage solution and the lactated Ringer poststorage rinse solution. Results: Serum alanine aminotransferase release increased from approximately $60 \mathrm{U} / \mathrm{L}$ before implantation to 750, 1410 , and $2520 \mathrm{U} / \mathrm{L}$ after full-size, half-size, and quarter-size transplantation, respectively. Total bilirubin increased slightly after transplantation of full-size and half-size grafts but increased 104-fold in quarter-size grafts. In quarter-size grafts, histological changes included necrosis, leukocyte infiltration, and eosinophilic inclusion body formation. Polyphenol treatment ameliorated these effects by $\geq 67 \%$. Survival was $30 \%$ after transplantation of small-for-size grafts. After polyphenol treatment, survival increased to $70 \%$. Free radicals in bile assessed by spin trapping and 4-hydroxynonenal adducts measured by immunohistochemistry were also greater in reduced-size grafts, an effect ameliorated by polyphenols. Epicatechin, a major polyphenol from Camellia sinenesis, also improved graft function and decreased enzyme release, histopathologic changes, and free radical formation. Conclusions: Increased formation of free radicals occurs after transplantation of reducedsize livers, which contributes to graft dysfunction and failure. Plant polyphenols decrease liver graft injury and increase survival of small-for-size liver grafts, most likely by scavenging free radicals.

A severe shortage of donor livers strictly limits liver transplantation and results in an increasing number of patients on waiting lists. ${ }^{1-4}$ To overcome this shortage, clinical application of living-related transplantation and split-liver transplantation has expanded in recent years. ${ }^{5-7}$ In living-related liver transplantation, grafts are obtained by partial hepatectomy from living donors. This technique was first used in pediatric patients ${ }^{8-10}$ but has been expanded to adult patients. ${ }^{5}$ In split-liver transplantation, 2 separate grafts obtained from a single cadaveric liver are transplanted into 2 patients. ${ }^{11}$ This technique, if it could be used in all situations, would theoretically double the donor organ pool and dramatically alleviate the shortage of donor organs. ${ }^{12,13}$ Because of the use of split-liver transplantation, the mortality of pediatric patients on the waiting list decreased from $>15 \%$ to $<2 \%$ in the transplantation program at the University of Hamburg. ${ }^{14}$

Survival and function of partial-liver grafts after transplantation depend highly on the relative graft mass implanted. ${ }^{5}$ If a graft is too small (so-called small-for-size graft) — namely, if the ratio of graft volume to standard liver volume is $<30 \%$ to $40 \%$ - survival decreases, and patients develop severe complications. ${ }^{5,15-19}$ Small-forsize grafts increase the difficulty of graft size matching and limit the use of the donor pool. Therefore, strategies that decrease the critical liver graft volume sufficient for survival and good function of partial grafts would benefit patients and lead to improved efficiency of donor pool use.

The mechanisms that underlie failure and poor function of small-for-size grafts remain unclear. Previous studies have indicated that reperfusion injury is important in primary graft nonfunction after full-size liver transplantation (see review ${ }^{20}$ ). Reperfusion injury and free-radical production may also play a role in primary

\section{$\dagger$ Deceased}

Abbreviations used in this paper: ESR, electron spin resonance; PAS, periodic acid-Schiff; 4-POBN, $\alpha$-(4-pyridyl 1-oxide)-N-tert-butylnitrone; TUNEL, terminal deoxynucleotidyl transferase-mediated deoxyuridine triphosphate nick-end labeling; UW, University of Wisconsin.

(C) 2005 by the American Gastroenterological Association $0016-5085 / 05 / \$ 30.00$ doi:10.1053/j.gastro.2005.05.060 
graft failure of small-for-size liver grafts. Indeed, glutathione levels rapidly decrease after in situ split-liver transplantation, and this suggests increased oxidative stress. $^{21}$ Antioxidant therapy might, therefore, be an effective strategy to minimize injury to small-for-size grafts. Previous studies show that plant polyphenols from Camellia sinenesis (green tea) are efficient free-radical and singlet oxygen scavengers ${ }^{22,23}$ and decrease liver injury after hepatic warm ischemia/reperfusion and transplantation of fatty livers. ${ }^{24,25}$ Accordingly, this study was designed to test the hypothesis that free-radical production increases after small-for-size liver transplantation to cause graft injury and that radical scavenging by polyphenols can ameliorate this free radical-dependent damage.

\section{Materials and Methods}

\section{Reduced-Size Liver Transplantation}

Male Lewis rats $(170-200 \mathrm{~g})$ were used as donors in liver transplantation experiments. Rats were anesthetized with ether, and full-size and reduced-size liver transplantation was performed as described previously. ${ }^{26}$ Briefly, for all transplantations, heparin (200 IU) in $0.5 \mathrm{~mL}$ of Ringer solution was injected into the subhepatic vena cava. A 4-mm-long stent prepared from polyethylene tubing (PE-50; Dickinson Co, Sparks, MD) was inserted into the common bile duct and secured with a 6-0 suture. Each liver was then flushed in situ with $5 \mathrm{~mL}$ of University of Wisconsin (UW) cold storage solution $\left(0^{\circ} \mathrm{C}-1^{\circ} \mathrm{C}\right.$; Barr Laboratories Inc, Pomona, NY). Venous cuffs prepared from 14-gauge intravenous catheters were placed over the subhepatic vena cava and the portal vein. For reduced-size liver transplantation, the left portion of the median lobe, the left lateral lobe, and the anterior and posterior caudate lobes were removed from the liver explant after ligation with 4-0 silk suture. This technique decreases liver mass by approximately $50 \% .^{26}$

In clinical living donor transplantation, cold preservation time is approximately 2 to 6 hours. ${ }^{27}$ In split-liver transplantation, cold storage time ranged from 2 to 17 hours, with a median cold storage time of approximately 8 hours. ${ }^{28}$ Therefore, in this study, full-size and reduced-size liver explants were weighed, stored in UW solution at $0^{\circ} \mathrm{C}-1^{\circ} \mathrm{C}$ for 6 hours, and rinsed with lactated Ringer solution just before implantation. In some experiments, an extract from $C$ sinenesis (Taiyo Kagaku Co, Yokkaichi, Mie, Japan) containing 85\% polyphenols by weight was dissolved in the UW cold storage solution and lactated Ringer solution $(20 \mu \mathrm{g} / \mathrm{mL}$; Abbott Laboratories, North Chicago, IL) for rinsing grafts before implantation. Polyphenols in the extract included epigallocatechin gallate (47.2\% of total polyphenols), epigallocatechin (11.0\%), gallocatechin gallate $(11.0 \%)$, epicatechin gallate $(10.8 \%)$, gallocatechin $(8.6 \%)$, epicatechin $(8.4 \%)$, and catechin $(3.0 \%)$. In other experiments, epicatechin, one of the major polyphenols from $C$ sinenesis, was dissolved in lactated Ringer solution at a final concentration of $17 \mu \mathrm{g} / \mathrm{mL}$, corresponding to a polyphenol content equivalent to $20 \mu \mathrm{g} / \mathrm{mL}$ of green tea extract and used to rinse grafts before transplantation.

Partial grafts were implanted into recipients of similar $(170-200 \mathrm{~g})$ or greater $(350-420 \mathrm{~g})$ body weight, thus resulting in a graft weight/standard liver weight (defined as $4 \%$ body weight) of approximately 25\% (quarter-size) and $50 \%$ (half-size), respectively. The whole grafts were implanted into recipients with body weights similar to those of the donors $(170-200 \mathrm{~g})$ as full-size controls. For the sham operation, rats received anesthesia, and the ligaments around the liver were dissected. Fifty minutes later, the abdominal wall was closed with a running suture without transplantation. Relative graft sizes in different groups were as follows: $99.7 \% \pm 4.8 \%$ (mean $\pm \mathrm{SEM}$ ) in the full-size group, $49.2 \% \pm 2.0 \%$ in the half-size group, $24.6 \% \pm 1.0 \%$ in the quarter-size group, $26.2 \% \pm$ $1.9 \%$ in the quarter-size group treated with polyphenols $(P>$ .05 compared with the untreated quarter-size group), and $25.6 \% \pm 0.5 \%$ in the quarter-size group treated with epicatechin $(P>.05$ compared with the untreated quarter-size group). Rats were observed for 2 weeks for survival after surgery. All animals were given humane care by using protocols approved by the Institutional Animal Care and Use Committee of the University of North Carolina at Chapel Hill.

\section{Detection of Free-Radical Adducts}

To assess free-radical formation, the spin-trapping reagent $\alpha$-(4-pyridyl 1 -oxide)-N-tert-butylnitrone (4-POBN; 1 $\mathrm{g} / \mathrm{kg}$ body weight) was dissolved in $1 \mathrm{~mL}$ of normal saline and injected slowly into the tail vein after opening the vascular clamps after implantation. Bile was collected via a cannula (PE-50) placed in the common bile duct into $50 \mu \mathrm{L}$ of ice-cold chelator solution containing $30 \mathrm{mmol} / \mathrm{L}$ dipyridyl (Sigma Chemical, St Louis, MO) and $30 \mathrm{mmol} / \mathrm{L}$ bathocuproinedisulfonic acid (Aldrich Chemical Co, Milwaukee, WI) for 1.5 hours after implantation and was stored at $-80^{\circ} \mathrm{C}$ until analysis. Bile samples were thawed, and free-radical adducts were detected with a Bruker EMX electron spin resonance (ESR) spectrometer (Bruker Scientific Instruments, Billerica, MA), as previously described. ${ }^{24,25}$ Free-radical adducts were quantified by measuring the average amplitudes of the left doublets of the ESR spectra. ${ }^{29}$

\section{Serum Alanine Aminotransferase and Total Bilirubin}

To assess (alanine aminotransferase) (ALT) release and accumulation of total bilirubin due to liver injury, postoperative blood samples were collected from the tail vein 18, 24, and 38 hours after implantation. Serum was obtained by centrifugation and stored at $-80^{\circ} \mathrm{C}$. ALT activity and total bilirubin were determined by analytical kits from Sigma Chemical. ALT levels are affected by the size of graft, which releases the enzyme, and the volume of recipient's blood, which is the reservoir of the released ALT. To adjust for the effect of graft size and recipient blood volume, ALT levels were normalized by multiplying by the recipient's standard blood volume ( $6.4 \%$ of body weight) and dividing by graft weight. ${ }^{30}$ 


\section{Histology and Histochemical Staining for Terminal Deoxynucleotidyl Transferase- Mediated Deoxyuridine Triphosphate Nick- End Labeling, 4-Hydroxynonenal Adducts, Myeloid Cell Antigen ED-1, Myeloperoxidase, Fibrinogen, and $\alpha_{1}$-Antitrypsin}

At various times after implantation, rats were anesthetized with pentobarbital ( $50 \mathrm{mg} / \mathrm{kg}$ intraperitoneally), their abdomens were opened, and the portal veins were cannulated with a 24-gauge intravenous catheter. The livers were rinsed with $10 \mathrm{~mL}$ of normal saline and perfusion-fixed with $10 \mathrm{~mL}$ of $4 \%$ paraformaldehyde (Sigma) in Dulbecco's phosphatebuffered saline (Invitrogen Corp, Grand Island, NY). Tissue blocks were placed in $4 \%$ paraformaldehyde for 48 hours before imbedding in paraffin. In sections stained with H\&E, necrotic areas were quantified by image analysis with a Universal Imaging Corp (West Chester, PA) Image-1/AT image acquisition and analysis system incorporating an Axioskop 50 microscope (Carl Zeiss, Inc, Thornwood, NY) and a $10 \times$ objective lens. Some sections were stained with periodic acidSchiff (PAS) staining to assess glycogen and glycoproteins. Apoptosis was assessed by labeling DNA strand breaks immunohistochemically using an In Situ Cell Death Detection Kit with anti-fluorescein antibody conjugated to alkaline phosphatase (Roche Diagnostics Corp, Indianapolis, IN) according to the manufacturer's instructions. Alkaline phosphatase activity was shown with fast red chromagen $(0.25 \mathrm{mg} / \mathrm{mL}$ in $0.1 \mathrm{~mol} / \mathrm{L}$ Tris-HCl buffer, $\mathrm{pH}$ 8.2; Roche Diagnostics) for 9 minutes at room temperature. Terminal deoxynucleotidyl transferase-mediated deoxyuridine triphosphate nick-end labeling (TUNEL)positive and -negative cells were counted in 10 randomly selected fields by using a $10 \times$ objective lens.

To detect 4-hydroxynonenal adducts, a marker of lipid peroxidation, ${ }^{31}$ sections were deparaffinized with xylene (Mallinckrodt Baker, Paris, KY) and taken through a graded series of alcohol and water mixtures to rehydrate the tissue. Hydrated sections were then exposed to mouse anti-4hydroxynonenal monoclonal antibodies (Alpha Diagnostic, San Antonio, TX) at a 1:500 dilution in $0.1 \mathrm{~mol} / \mathrm{L}$ phosphate buffer/Tween for 30 minutes at room temperature. Peroxidaseconjugated anti-mouse immunoglobulin G1 antibody (Dako Corp, Carpinteria, CA) was then applied, and 3,3'-diaminobenzidine chromagen was added as the peroxidase substrate. After the immunostaining procedure, a light counterstain of modified Mayer hematoxylin (American Master Tech Scientific, Lodi, CA) was applied so that 4-hydroxynonenal-labeled cells could be identified easily. Immunohistochemistry of the myeloid cell antigen ED-1, a marker of infiltrating monocytes/ macrophages, and myeloperoxidase, a marker of neutrophils, was performed with a monoclonal primary antibody against ED-1 (1:250; Serotek, Raleigh, NC) for 1 hour at room temperature and a primary rabbit antibody against myeloperoxidase (1:200; Dako) for 30 minutes. Immunohistochemical staining of fibrinogen and $\alpha_{1}$-antitrypsin was performed with primary antibodies against fibrinogen and $\alpha_{1}$-antitrypsin (Dako) at dilutions of 1:500 for 30 minutes.

\section{Statistical Analysis}

All groups were compared by using the Fisher exact test or analysis of variance plus the Student-Newman-Keuls test as appropriate. Data are shown as means \pm SEM. Differences were considered significant at the $P<.05$ level.

\section{Results}

\section{Transaminase Release Is Greater and Graft Function Is Poorer in Small-for-Size Grafts After Liver Transplantation: Reversal by Polyphenols}

Graft injury was assessed by the release of ALT into the blood after liver transplantation. Before implantation, serum ALT was approximately $60 \mathrm{U} / \mathrm{L}$. Eighteen hours after implantation, ALT increased to 750,1410 , and $2520 \mathrm{U} / \mathrm{L}$ in full-size, half-size, and quarter-size grafts, respectively (Figure 1A). At 38 hours after implantation, ALT decreased gradually to 310 and $390 \mathrm{U} / \mathrm{L}$ in rats that received full-size and half-size grafts, but ALT increased to $1940 \mathrm{U} / \mathrm{L}$ in rats that received quartersize grafts (Figure 1A). ALT was markedly higher after transplantation of quarter-size grafts despite the 4-fold and 2-fold smaller relative liver mass compared with full-size and half-size grafts. After adjusting for graft weight and each recipient's standard blood volume, ${ }^{30}$ ALT levels increased from $0.1 \mathrm{U} / \mathrm{g}$ liver in sham-operated rats to $1.2,4.5$, and $14.1 \mathrm{U} / \mathrm{g}$ in rats that received full-size, half-size, and quarter-size grafts, respectively (Figure $1 B$ ). Polyphenols, which are potent free-radical scavengers, decreased peak ALT to $4.7 \mathrm{U} / \mathrm{g}$ in rats implanted with quarter-size liver grafts, a $67 \%$ decrease compared with the quarter-size graft without polyphenol treatment (Figure 1B). Epicatechin, a major component of $C$ sinenesis polyphenols, also decreased peak ALT by $53 \%$ (Figure $1 B$ ). These effects indicated that polyphenol treatment markedly reduced injury to quarter-size grafts.

Serum total bilirubin increases with poor liver function. Before implantation, bilirubin was $0.07 \mathrm{mg} / \mathrm{dL}$ Thirty-eight hours after implantation of quarter-size liver grafts, bilirubin increased 104-fold. By contrast, bilirubin was not significantly increased in rats that received full-size and half-size grafts (Figure 2A). Peak bilirubin levels, adjusted by graft weight and recipient standard blood volume, increased from $0.002 \mathrm{mg} / \mathrm{g}$ liver in sham-operated rats to $0.46 \mathrm{mg} / \mathrm{g}$ liver in rats that received quarter-size grafts (Figure $2 B$ ). Polyphenols decreased peak bilirubin by $80 \%$ to $0.09 \mathrm{mg} / \mathrm{g}$ liver in rats that received quarter-size liver grafts (Figure $2 B$ ). Epi- 


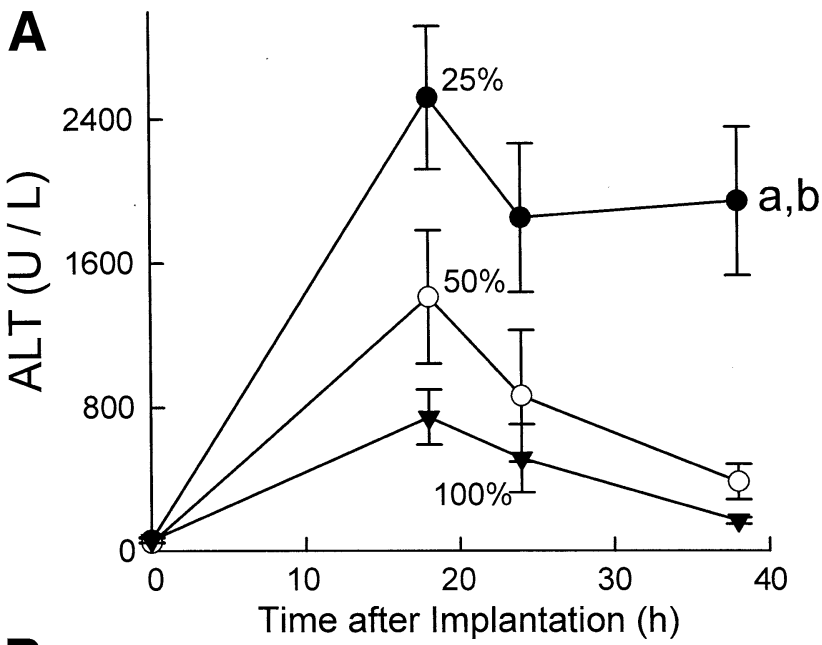

left panel). After implantation of quarter-size liver grafts, severe focal necrosis developed, mainly in the periportal and midzonal regions of the liver lobule (Figure 3, middle right panel). In areas adjacent to the necrotic areas, eosinophilic inclusions were observed in hepatocytes (Figure 3, lower right panel $A$ ). These inclusion bodies stained weakly with PAS (Figure 3, lower right panel $B$ ), and some were positive for fibrinogen (Figure 3, lower right panel $C$ ) and $\alpha_{1}$ antitrypsin (Figure 3, lower right panel $D$ ). By contrast, focal necrosis and eosinophilic inclusion bodies were rarely detected in full-size and half-size grafts
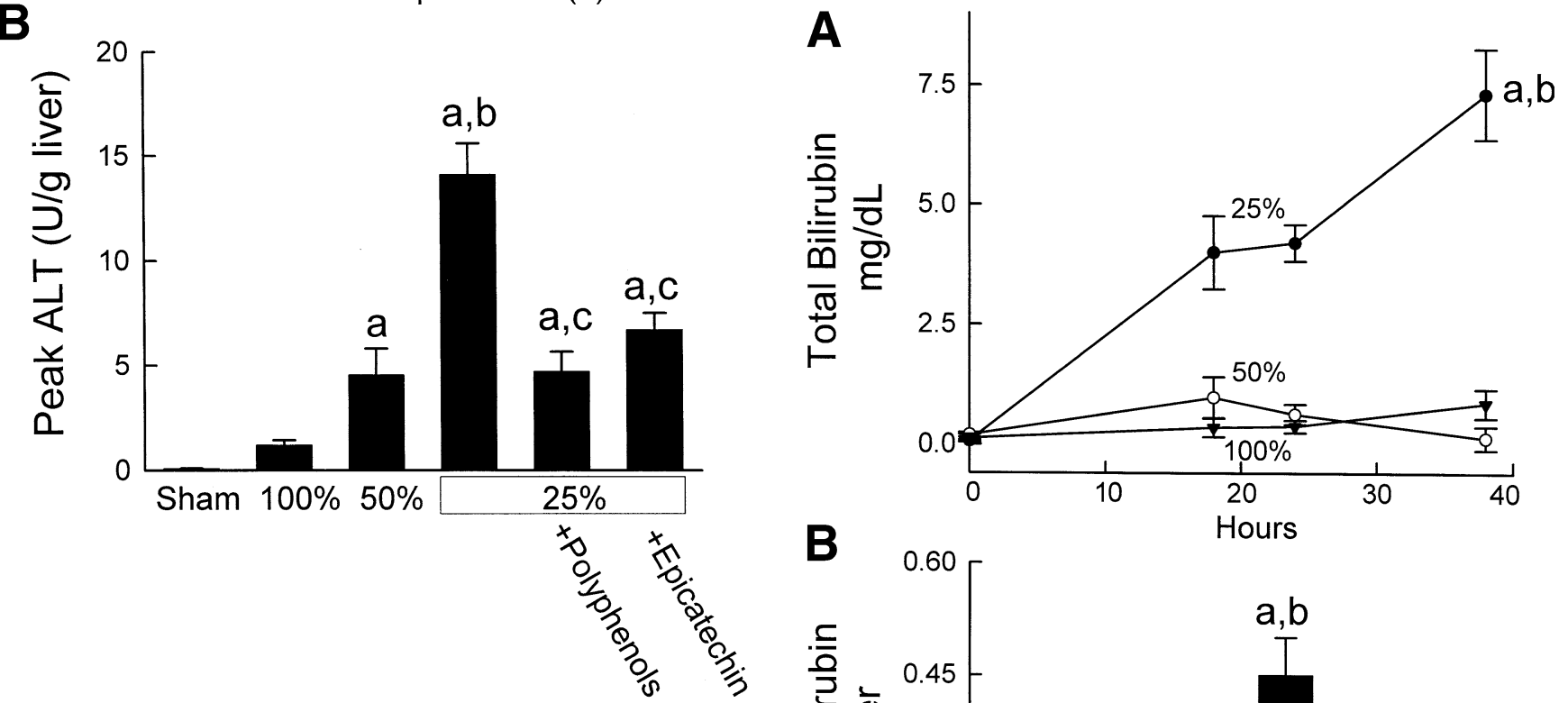

Figure 1. Polyphenols protect against alanine aminotransferase release after transplantation of small-for-size liver grafts. Rat liver explants were stored in cold UW solution for 6 hours before implantation. In some experiments, a polyphenol extract from Camellia sinenesis $(20 \mu \mathrm{g} / \mathrm{mL})$ or epicatechin $(17 \mu \mathrm{g} / \mathrm{mL})$ was added to the storage and rinse solution, as described in Methods. Whole and half-size explants were implanted into recipients of similar or greater body weight, resulting in relative graft sizes (graft weight/standard liver weight) of approximately 100\% (full-size), 50\% (half-size), and $25 \%$ (quarter-size). Blood samples were collected at 18, 24, and 38 hours after implantation for ALT measurement. The time course of serum ALT is shown in $(A)$. Peak ALT, adjusted for graft weight and the recipient's standard blood volume, is shown in $(B)$. Group sizes were 4 to 7 livers per group. a, $P<.05$ vs full-size $(100 \%)$; b, $P<.05$ vs half-size (50\%); c, $P<.05$ vs quarter-size (25\%).

catechin also decreased peak bilirubin to $0.1 \mathrm{mg} / \mathrm{g}$ liver in rats that received quarter-size liver grafts (Figure 2B).

\section{Polyphenols Minimize Hepatic Pathologic Changes and Increase Survival After Transplantation of Quarter-Size Liver Grafts}

No pathologic changes were observed in liver tissue 38 hours after sham operation (Figure 3, upper

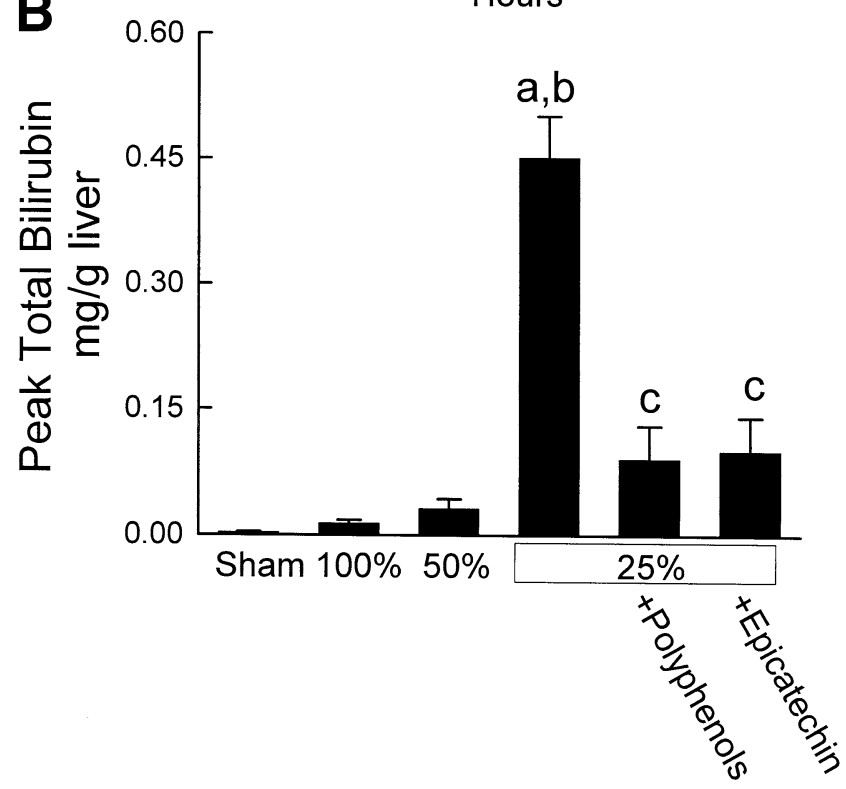

Figure 2. Polyphenols protect against increased serum total bilirubin after transplantation of small-for-size liver grafts. Full-size and reduced-size rat livers were transplanted as described previously. Blood samples were collected at 18,24 , and 38 hours after implantation for bilirubin measurement. The time course of serum bilirubin is shown in $(A)$. Peak bilirubin, adjusted for graft weight and the recipient's standard blood volume, is shown in $(B)$. Group sizes are 4 to 7 livers per group. a, $P<.05$ vs full-size (100\%); b, $P<.05$ vs half-size (50\%); c, $P<.05$ vs quarter-size $(25 \%)$. 

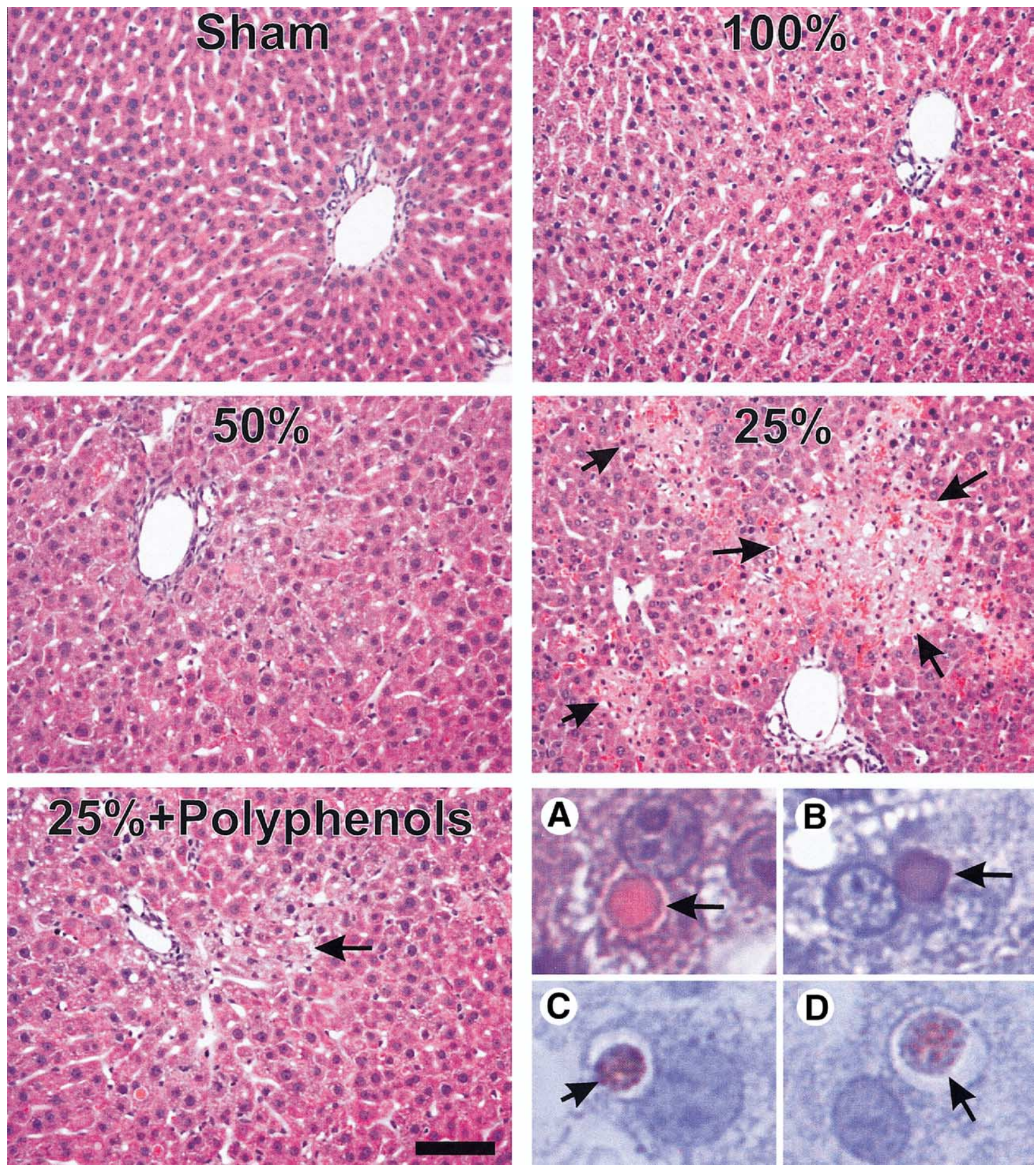

Figure 3. Polyphenols decrease necrosis in small-for-size liver grafts after transplantation. Full-size and reduced-size rat livers were transplanted as described previously. Thirty-eight hours after implantation, liver grafts were fixed, sectioned, and stained with H\&E. Arrows identify necrotic areas or inclusion bodies in the lower left panel. Panels are as follows: upper left, liver from a sham-operated rat; upper right, full-size liver graft; middle left, half-size liver grafts; middle right, quarter-size liver graft; lower left, quarter-size liver graft treated with polyphenols; and lower right, inclusion bodies in quarter-size liver grafts. The panels in the lower right panel are as follows: $(A)$ H\&E staining; $(B)$ PAS staining; $(C)$ fibrinogen staining; $(D) \alpha_{1}$-antitrypsin staining (bar $\left.=100 \mu \mathrm{m}\right)$.

(Figure 3, upper right and middle left panels). Image analysis showed that necrotic areas constituted $13 \%$ of total liver tissue in quarter-size grafts, compared with approximately $2 \%$ in full-size and half-size grafts
(Figure 4). Polyphenols decreased necrotic areas in quarter-size grafts to $2.7 \%$, which was not statistically different from untreated full-size and half-size grafts (Figure 3, lower left panel, and Figure 4). Epicatechin 


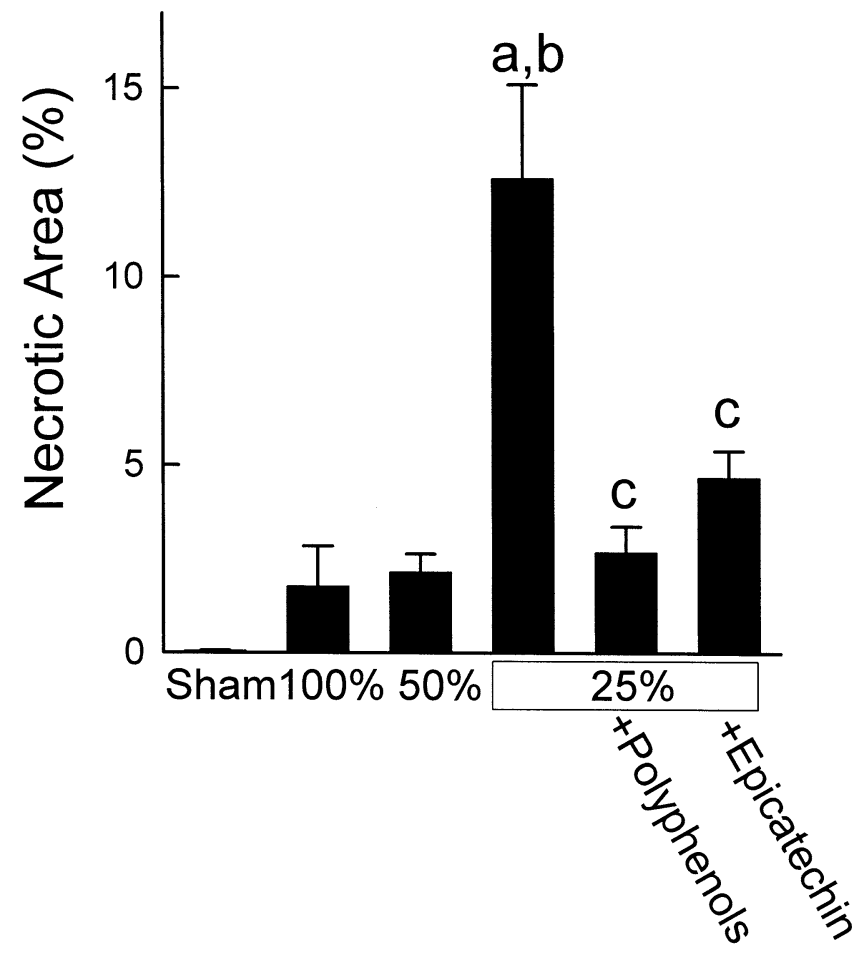

Figure 4. Polyphenols protect against necrosis after transplantation of small-for-size liver grafts. Rat livers were transplanted and prepared for histology as described previously, and necrotic areas were quantified by image analysis as described in Methods. Group sizes were 4 to 5 livers per group. a, $P<.05$ vs full-size $(100 \%)$; $b, P<.05$ vs half-size (50\%); c, $P<.05$ vs quarter-size (25\%).

also decreased necrotic areas in quarter-size grafts to 4.7\% (Figure 4).

Apoptosis in liver sections was detected by TUNEL labeling of DNA. TUNEL-positive cells were rare $(0.15 \%)$ in livers from sham-operated animals. Five hours after implantation of full-size and half-size liver grafts, TUNEL-positive cells increased slightly to $0.65 \%$ and $0.52 \%$ in full-size and half-size grafts, respectively $(P<.05$ vs sham $)$. After quarter-size liver transplantation, TUNEL-positive cells were $0.26 \%$ without polyphenol treatment, $0.37 \%$ with polyphenol treatment, and $0.35 \%$ with epicatechin treatment-changes that were not significantly different from sham-operated livers. No further increase in TUNEL labeling occurred at 18 and 38 hours after implantation (data not shown). Taken together, these findings indicated that increased cell killing after quarter-size liver transplantation was mainly due to necrosis.

To assess infiltration of leukocytes after implantation, immunohistochemical staining was performed to detect the myeloid cell antigen ED-1, a marker of infiltrating monocytes/macrophages, and myeloperoxidase, an indicator of neutrophils. After sham operation, a few (1.5 cells per high-power field) ED-1-positive cells were present in the liver (Figure 5, upper left panel). At 38 hours after implantation, ED-1-positive cells increased to $4.2,4.7$, and 13.2 cells per high-power field in fullsize, half-size, and quarter-size grafts, respectively (Figure 5, upper right, middle left, and middle right panels). This increase of infiltrating monocytes/macrophages in quarter-size grafts was blunted by polyphenol (Figure 5, lower left panel) and epicatechin (Figure 5, lower right panel) treatments. Similar changes were observed for myeloperoxidase-positive cells (data not shown).

Because clinical small-for-size liver transplantation is associated with increased graft failure, we evaluated the effect of polyphenols on survival of partial-liver grafts. Survival rates were $100 \%$ and $80 \%$ after transplantation of full-size and half-size liver grafts, respectively. After transplantation of quarter-size grafts, survival decreased significantly to $30 \%$ (Figure 6). Death occurred mainly in the first 3 days after implantation. It is important to note that polyphenol treatment significantly increased survival of quarter-size grafts to $70 \%$ (Figure 6).

\section{Free-Radical Production and Lipid Peroxidation Increase After Transplantation of Partial-Liver Grafts: Prevention by Polyphenols}

Free radicals likely play a role in graft injury after transplantation. Accordingly, free radicals were trapped by using a spin-trapping reagent and detected by ESR . In bile samples from rats that received full-size liver grafts, a small 6-line ESR spectrum due to a 4-POBN/ radical adduct was detected (Figure 7 , upper panel $A$ ). The amplitude of this signal increased slightly after transplantation of half-size grafts but increased 4.5 -fold after transplantation of quarter-size grafts (Figure 7 , upper panel $B$ and $C$ and lower panel). Computer simulation of the spectrum (Figure 7, upper panel $D$ ) was accomplished by using hyperfine coupling constants of $a^{\mathrm{N}}=15.60 \mathrm{G}$ and $a_{\beta}^{\mathrm{H}}=2.70 \mathrm{G}$. Such coupling constants are characteristic of a carbon-centered 4-POBN radical adduct. These coupling constants matched the closely coupling constants $\left(a^{\mathrm{N}}=15.63 \mathrm{G} ; a^{\mathrm{H}}{ }_{\beta}=2.73\right.$ $\mathrm{G}$ ) obtained from the bile of rats given 4-POBN and oxidized polyunsaturated fatty acids. ${ }^{32}$ Similar coupling constants describe the ESR spectra of carbon-centered 4-POBN radical adducts produced after fatty liver transplantation. ${ }^{33}$ It is important to note that polyphenol treatment blunted this increase of the ESR signal after transplantation of quarter-size grafts by $55 \%$ (Figure 7 , upper panel $E$ and lower panel) and that epicatechin blunted this increase of the ESR signal by 39\% (Figure 7, upper panel $F$ and lower panel). 

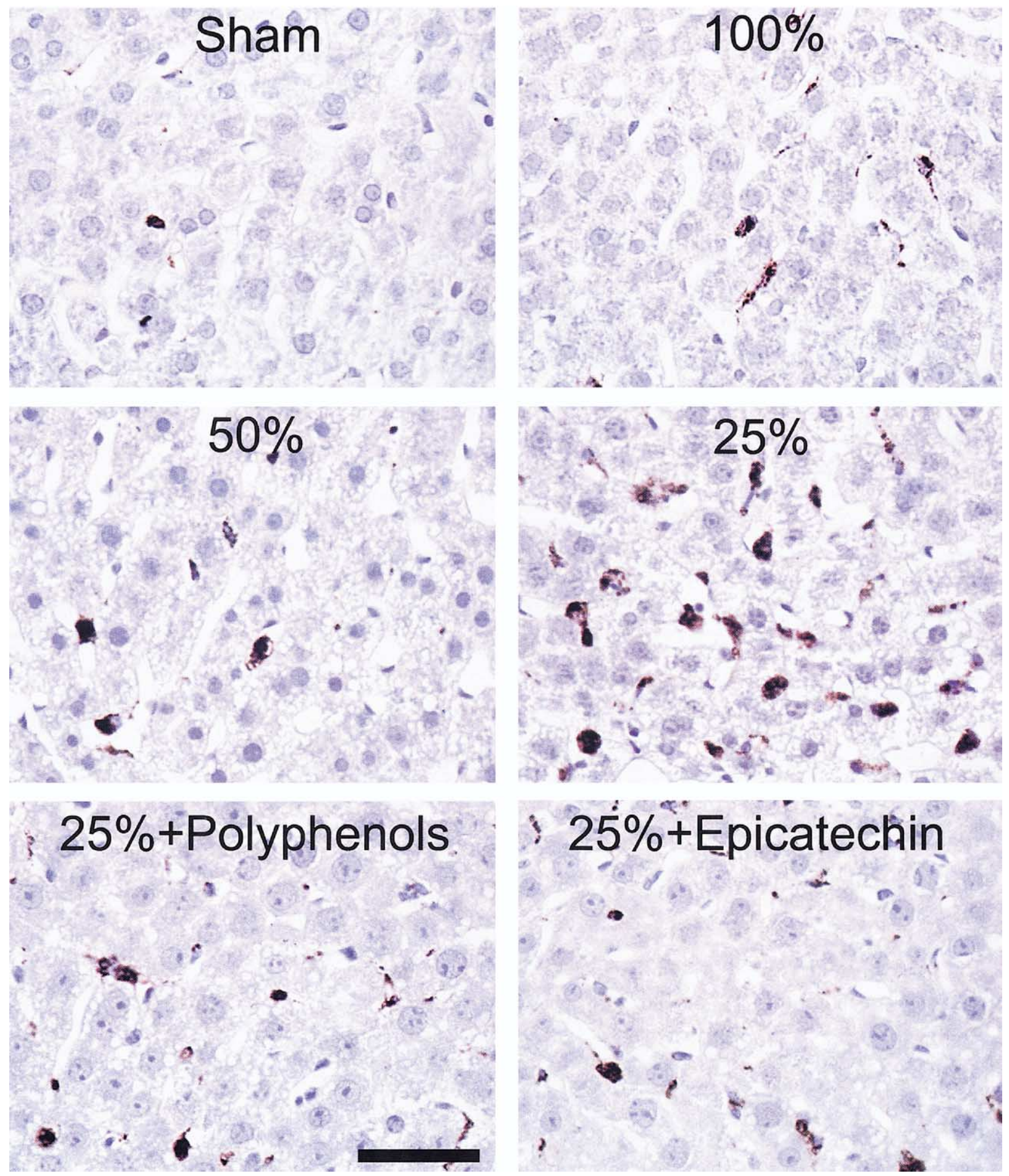

Figure 5. Monocyte/macrophage infiltration after transplantation of small-for-size liver grafts. Rat livers were transplanted and prepared for histology as described previously, and ED-1, a marker of infiltrating monocytes/macrophages, was detected in sections by immunohistochemical staining. Panels are as follows: upper left, liver from a sham-operated rat; upper right, full-size liver graft; middle left, half-size liver graft; middle right, quarter-size liver graft; lower left, quarter-size liver graft treated with polyphenols; lower right, quarter-size liver graft treated with epicatechin $($ bar $=50 \mu \mathrm{m})$.

Liver grafts were also immunostained for 4hydroxynonenal adducts, an end product of lipid peroxidation. After sham operation, 4-hydroxynonenal adducts were barely detectable (Figure 8, upper left panel). After transplantation of full-size and half-size grafts, 4-hydroxynonenal adducts increased slightly in comparison to the sham operation, mainly in the pericentral regions (Figure 8, upper right and middle left panels). By con- 
trast, 4-hydroxynonenal adduct staining increased markedly after transplantation of quarter-size grafts, predominantly in the periportal and midzonal regions (Figure 8, middle right panel). The hydroxynonenal-positive area increased from $1.4 \%$ in livers from rats receiving sham operation to $6.6 \%, 9.5 \%$, and $28.1 \%$ after transplantation of full-size, half-size, and quarter-size grafts (Figure 9). Treatment of the quarter-size grafts with polyphenols decreased the 4-hydroxynonenal-positive area to 3.2\% (Figure 8, lower left panel, and Figure 9). Epicatechin also decreased the 4-hydroxynonenal-positive area to 7.6\% (Figure 8, lower right panel, and Figure 9).

\section{Discussion}

\section{Graft Injury Increases in Small-for-Size Liver Grafts After Liver Transplantation}

The graft size relative to the recipient's body weight is a critical factor for survival and good function in partial-liver transplantation. ${ }^{5}$ Small-for-size grafts are associated with decreased survival and increased complications after clinical partial-liver transplantation. ${ }^{15,16}$ In the last several years, adult-to-adult living donor liver

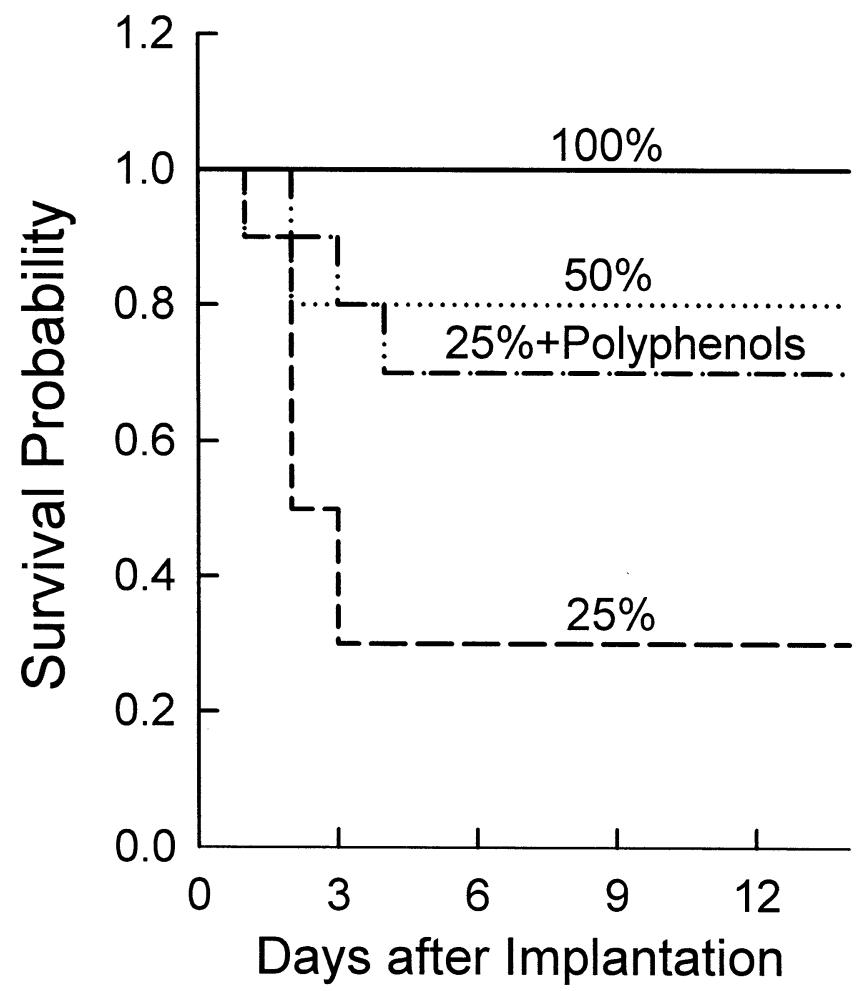

Figure 6. Polyphenols increase survival of small-for-size grafts after transplantation. Full-size and reduced-size rat livers were transplanted as described previously. Rats were observed 2 weeks after transplantation for survival. Survival of untreated quarter-size grafts was significantly less that that of full-size and half-size grafts, and survival of quarter-size grafts treated with polyphenols was significantly greater than that of untreated quarter-size grafts $(P<.05$; Fisher exact test).
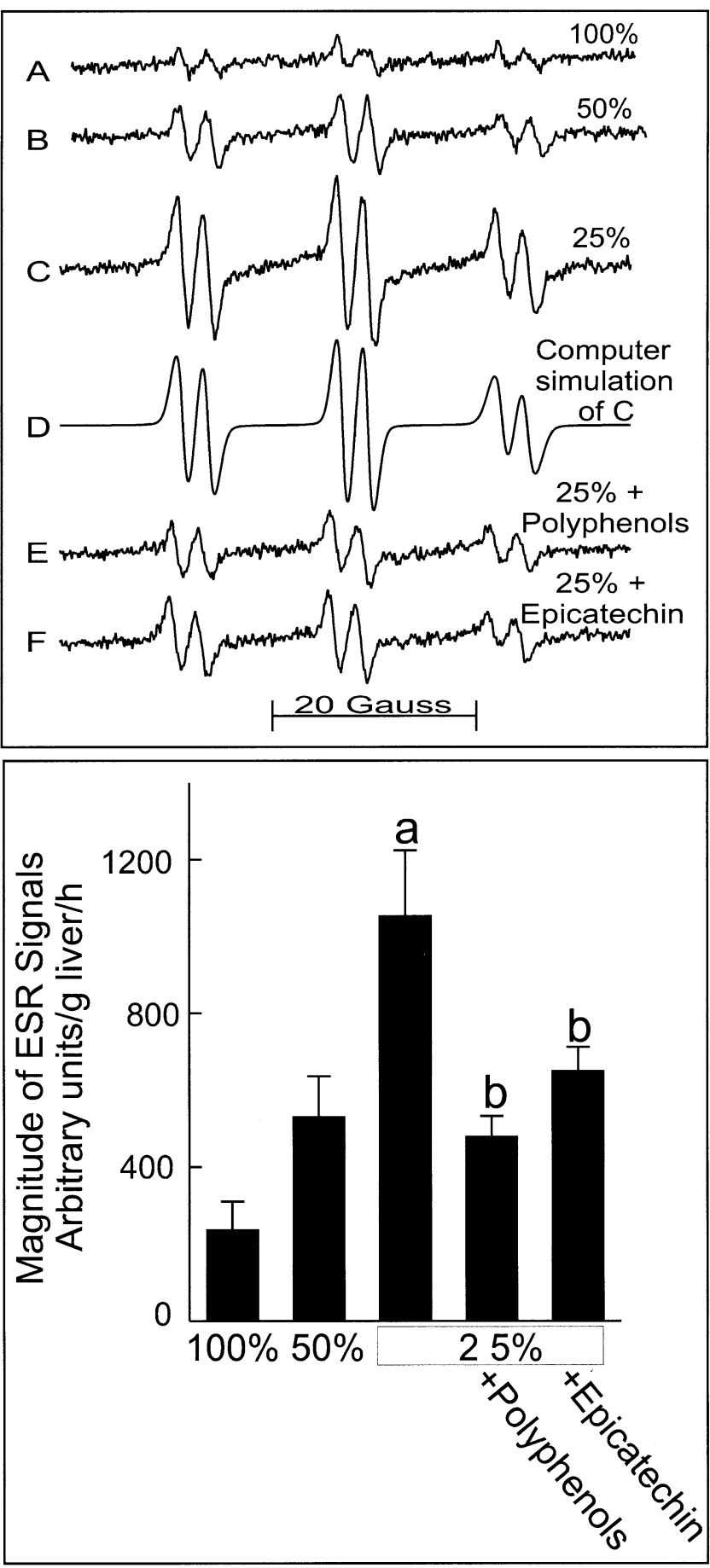

Figure 7. Electron spin resonance spectra of free-radical adducts in bile after liver transplantation. Full-size and reduced-size rat livers were transplanted as described previously. The spin-trapping reagent 4-POBN (1 g/kg) was injected slowly into the tail vein of the recipient upon opening of the vascular clamps after implantation. Free-radical adducts in bile were detected and quantified as described in Methods. Typical spectra are shown in the upper panel. (A) Full-size graft $(100 \%) ;(B)$ half-size graft $(50 \%) ;(C)$ quarter-size graft $(25 \%) ;(D)$ computer simulation of $(C)$; $(E)$ quarter-size graft treated with polyphenols; $(F)$ quarter-size graft treated with epicatechin. Quantification of free-radical adducts is shown in the lower panel. a, $P<.05$ vs full-size (100\%); b, $P<.05$ vs half-size (50\%); c, $P<.05$ vs quarter-size (25\%). 

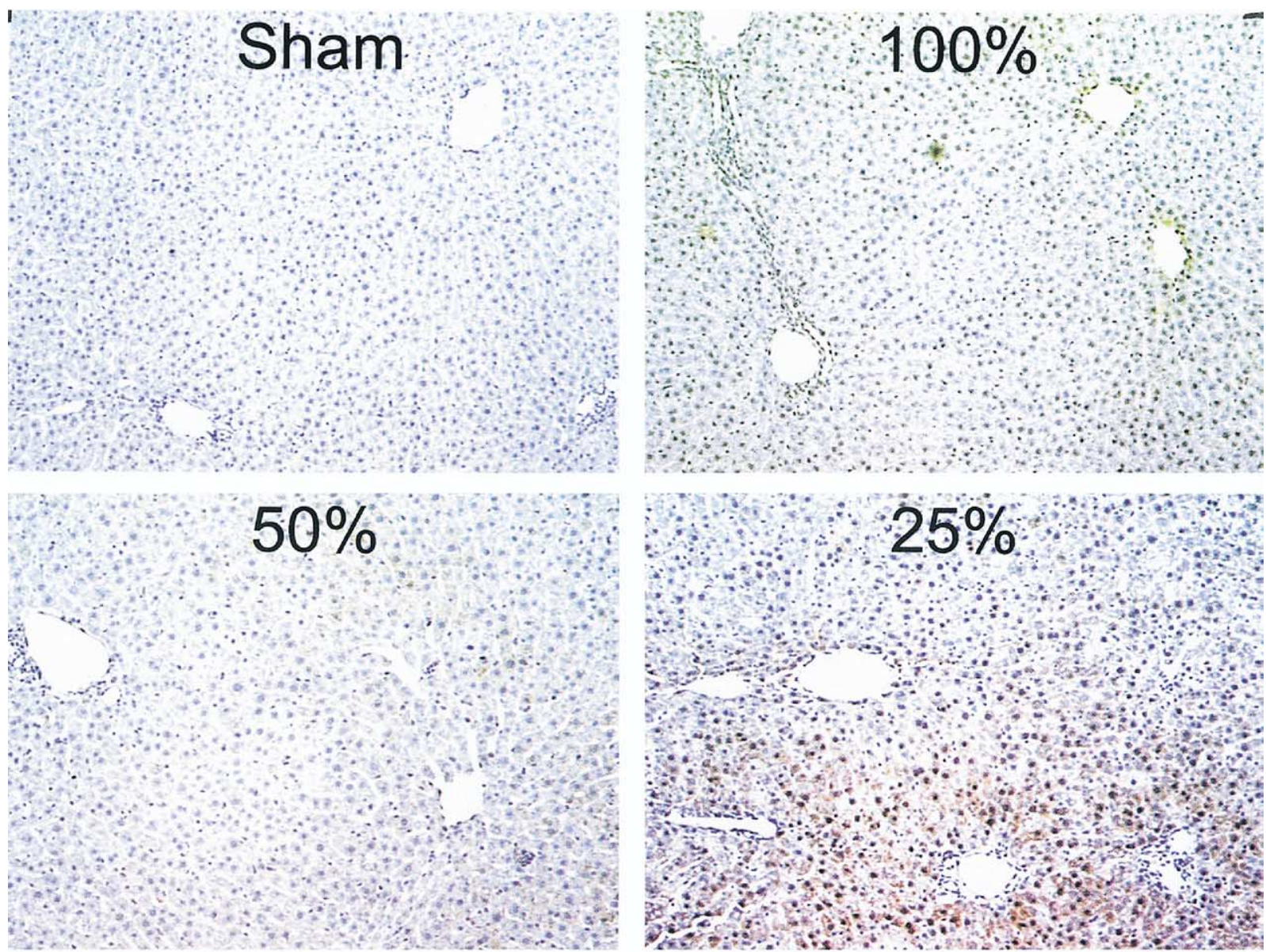

\section{$25 \%+$ Polyphenols}
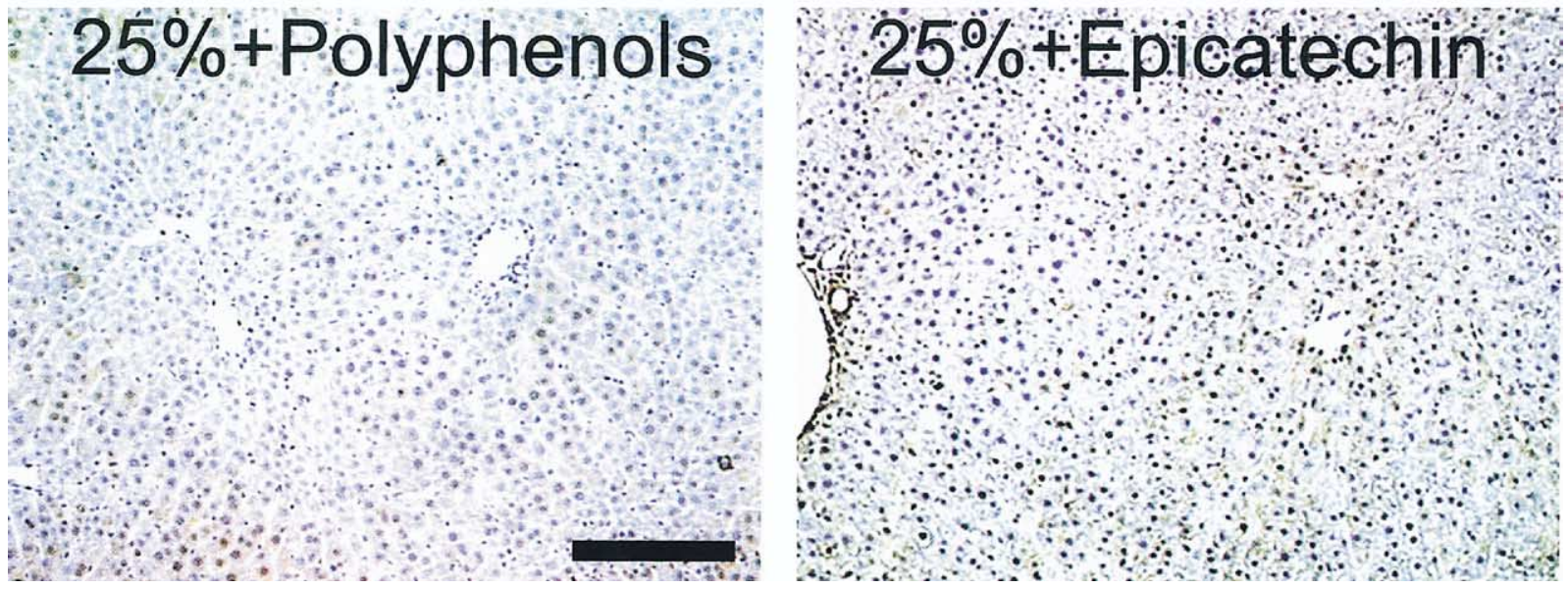

Figure 8. Polyphenols diminish 4-hydroxynonenal adduct formation in small-for-size liver grafts after transplantation. Rat livers were transplanted and prepared for histology as described previously, and 4-hydroxynonenal adducts were detected immunohistochemically as described in Methods. Panels are as follows: upper left, liver from a sham-operated rat; upper right, full-size liver graft; middle left, half-size liver graft; middle right, quarter-size liver graft; lower left, quarter-size liver graft treated with polyphenols; lower right, quarter-size graft treated with epicatechin (bar $=100 \mu \mathrm{m})$.

transplantation has increased rapidly. $5,16,34$ A major limitation of living donor liver transplantation for an adult recipient is the adequacy of size of the graft that can be harvested from a living donor. ${ }^{17}$ A transplantation surgeon can face the dilemma that a small-for-size graft from a living donor may be inadequate to meet the metabolic demands of an adult recipient, yet removal of more liver might increase the risk to the donor. In split-liver transplantation, livers are divided into the right lobe, which can be implanted into a normal-sized adult, and the left lobe, which can only be implanted into a pediatric patient or a small-sized adult because of 


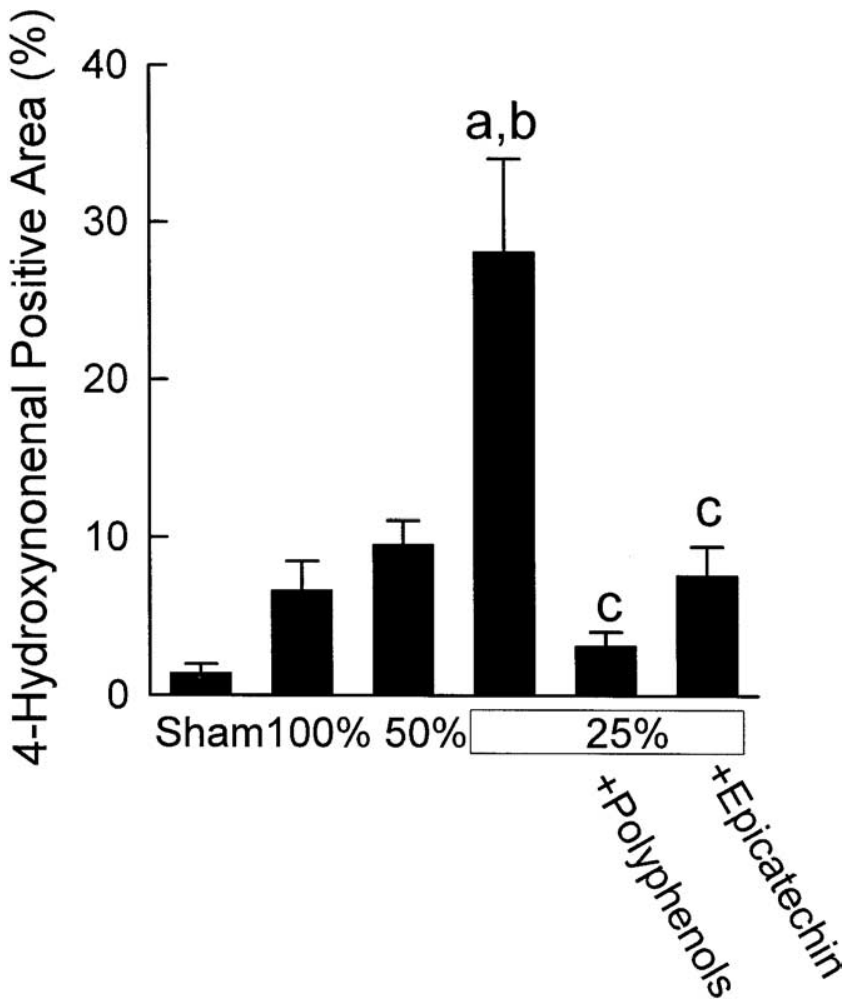

Figure 9. Polyphenols protect against lipid peroxidation after transplantation of small-for-size liver grafts. Rat livers were transplanted, prepared for histology, and stained for 4-hydroxynonenal adducts as described previously. 4-Hydroxynonenal-positive areas were quantified by image analysis as described in Methods. Group sizes were 4 livers per group. a, $P<.05$ vs full-size (100\%); $b, P<.05$ vs half-size (50\%); c, $P<.05$ vs quarter-size (25\%).

its small mass. Despite the robust ability of hepatic regeneration, small-for-size grafts lead to graft failure and severe postoperative complications, and this increases the difficulty of graft size matching and limits use of the donor pool.

An important issue in partial-liver transplantation is whether small grafts fail simply because they cannot meet the metabolic demands of the recipients or whether greater damage occurs to the small grafts during storage, reperfusion, and implantation. In this study, we showed that liver injury was not overt, graft function (bilirubin levels) was not significantly compromised, and graft survival was $\geq 80 \%$ in full-size and half-size rat liver grafts (Figures 1-4 and 6). By contrast, graft injury increased dramatically and graft function was compromised in quarter-size grafts, as indicated by high serum ALT release, necrosis in histological sections, leukocyte infiltration, and markedly increased bilirubin (Figures 1-5). Quarter-size transplantation was also associated with poor graft survival of $30 \%$ (Figure 6). These data support the hypothesis that greater damage does occur in smallfor-size liver grafts that leads to graft dysfunction and failure.
In quarter-size, but not full-size, grafts, eosinophilic inclusion bodies appeared in periportal and midzonal hepatocytes (Figure 3). How these eosinophilic inclusion bodies formed remains unclear. These inclusion bodies resemble the PAS-positive inclusion bodies described previously in association with increased sinusoidal pressure due to increased vascular resistance. ${ }^{35-39}$ Such conditions may lead to transient hypoxia, alterations of the hepatocyte cytoskeleton, and uptake of plasma proteins in endocytic vesicles. These vesicles then form inclusion bodies that contain the plasma glycoproteins fibrinogen and $\alpha_{1}$-antitrypsin. Accumulation of inclusion bodies may also reflect disruption of normal protein degradation or release processes or both, thus leading to glycoprotein accumulation.

\section{Free Radicals Play an Important Role in Failure of Small-for-Size Liver Grafts}

Oxidative stress plays an important role in liver injury after warm ischemia/reoxygenation and full-size liver transplantation. Free-radical production increases after hepatic warm ischemia/reperfusion ${ }^{24}$ and is higher after transplantation of livers stored under nonsurvival conditions than under survival conditions. ${ }^{40}$ Rinsing of grafts with Carolina rinse solution, which contains the antioxidants glutathione, desferrioxamine, and allopurinol, before implantation decreases free-radical generation and liver injury and improves survival. ${ }^{41,42}$ These findings suggest that free-radical formation plays a crucial role in graft failure. Furthermore, recent work shows that gene delivery of $\mathrm{Cu} / \mathrm{Zn}$-superoxide dismutase by using an adenovirus decreases the failure of liver grafts, ${ }^{43,44}$ again indicating a link between reactive oxygen species and graft failure.

Although extensive information has accumulated about the effects of oxidative stress in full-size liver transplantation, little is known about the role of free radicals in partial-liver transplantation. We found that free-radical adducts, detectable by ESR, were minimal in full-size liver grafts, most likely because of the short cold storage time. By contrast, free-radical signals increased markedly in quarter-size grafts compared with full-size and half-size liver grafts (Figure 7). Consistently, 4-hydroxynonenal, a marker of lipid peroxidation, also increased predominantly in small-for-size liver grafts (Figures 8 and 9). These findings show that free-radical production and lipid peroxidation increased markedly in small-for-size grafts. It is important to note that increased free-radical production was associated with more severe graft injury and failure of small-for-size grafts. 


\section{Possible Mechanisms of Free-Radical Formation in Small-for-Size Liver Grafts}

The mechanisms of increased free-radical production in partial-liver grafts remain to be clarified. Previous studies showed that extended cold storage increases freeradical production. ${ }^{40}$ However, cold storage times are relatively short in living donor transplantation. In quarter-size grafts, the metabolic burden is approximately 4 -fold in a partial graft. Mitochondria are important sources of oxygen radicals. ${ }^{45-47}$ As metabolism increases, mitochondria likely produce more oxygen radicals. In addition, antioxidant molecules, such as reduced glutathione, may be consumed more rapidly in a reduced-size graft than a full-size graft. As a result, resistance of partial grafts to oxidative stress may be compromised. In support of this hypothesis, a recent study ${ }^{21}$ showed that glutathione levels rapidly decreased after split-liver transplantation-an effect associated with increased graft injury.

Another possible source of increased free-radical production is Kupffer cells stimulated by endotoxin after partial-liver transplantation. Because relative blood flow to quarter-size grafts is 4 times that to full-size grafts, individual Kupffer cells may be exposed to 4 times the amount of endotoxin entering from the gut via the portal vein. Endotoxin is well characterized to activate Kupffer cells and neutrophils to produce reactive oxygen species. ${ }^{48,49}$ Activated Kupffer cells also produce tumor necrosis factor $\alpha,{ }^{49}$ which increases the formation of reactive oxygen species in mitochondria of hepatocytes. ${ }^{50}$ In addition, activated Kupffer cells produce proinflammatory cytokines and chemokines, thus increasing leukocyte adhesion. ${ }^{49}$ High blood flow rates may also increase vascular bed damage and lead to increased white blood cell adhesion. Indeed, we have observed increased infiltration of monocytes/macrophages and neutrophils in quarter-size grafts (Figure 5). Adherent white blood cells may be another important source of free radicals. Moreover, increased blood flow in partial-liver grafts may increase shear stress, which is also known to cause reactive oxygen species formation. ${ }^{51}$

Harvest of partial livers for reduced-size liver transplantation entails a more complicated and prolonged surgical procedure with greater manipulation of liver tissue and a longer time of warm ischemic stress. Manipulation during organ harvest disturbs the microcirculation and causes hypoxia in the graft, ${ }^{52}$ and this in turn activates Kupffer cells $s^{53}$ and increases free-radical production. ${ }^{54}$ These events are associated with a higher incidence of graft failure after transplantation. ${ }^{53}$ Thus, more extensive tissue manipulation during clinical par- tial-liver transplantation may contribute to greater graft injury and poorer function. However, in our study, freeradical production increased more in quarter-size grafts than in half-size grafts, although the surgical manipulation of the grafts was virtually identical (Figures 7-9). Therefore, enhanced free-radical production in quartersize grafts is probably not due to surgical manipulation.

\section{Polyphenols Decrease Free-Radical Formation and Improve Function and Survival of Reduced-Size Liver Grafts}

If free radical-dependent graft injury plays an important role in the failure of small-for-size grafts, then antioxidant treatment should prevent graft failure and improve function. Extracts of green tea are potent scavengers of reactive oxygen species and are superior in this regard to vitamins $\mathrm{C}$ and E. ${ }^{22}$ Previous studies from this laboratory show that polyphenols from $C$ sinenesis protect against liver injury caused by warm ischemia/reperfusion and transplantation of fatty livers. ${ }^{24,25}$ Polyphenols also decrease free radicals and inhibit production of proinflammatory cytokines in these models. ${ }^{24}$ Therefore, we evaluated the effects of polyphenols on injury to quartersize liver grafts. Polyphenol addition to the storage and rinse solution markedly decreased enzyme release, cellular necrosis, leukocyte infiltration, and graft dysfunction (Figures 1-4). Moreover, polyphenols increased survival from $30 \%$ to $70 \%$, nearly the same as for untreated half-size liver transplantation (Figure 6). These protective effects were associated with decreases in free-radical adducts and lipid peroxidation by polyphenols (Figures 7-9). Epicatechin, a major polyphenol component of the $C$ sinenesis extract, also minimized quarter-size graft injury after transplantation (Figures 1-4) and decreased free-radical adducts and lipid peroxidation (Figures 7-9). These results strongly support the notion that the protective effects of $C$ sinenesis extract are mediated by its polyphenolic contents.

Taken together, our data support the hypothesis that graft injury, dysfunction, and failure are greater in smallfor-size liver grafts because of the enhanced formation of reactive oxygen species. If this oxidative stress can be prevented, then the viability and function of small-forsize grafts improve markedly. In this report, antioxidant polyphenols substantially decreased graft injury and, therefore, could be a promising therapy to prevent dysfunction and failure of small-for-size liver grafts.

\section{References}

1. Neuberger J. Liver transplantation. J Hepatol 2000;32:198-207.

2. Van Thiel DH, Colantoni A, De Maria N, Fagiuoli S, Gasbarrini A Hassanein T. Liver transplantation in the United States: current 
problems and future goals. Ital J Gastroenterol 1996;28: 169-175.

3. Harper AM, Rosendale JD. The UNOS OPTN waiting list and donor registry. Clin Transpl 1997;61-80.

4. Patients on the UNOS National Patient Waiting List. UNOS Report 2004. Available at: http://www.optn.org/data. Accessed December 14, 2004.

5. Testa G, Malago M, Broelsch CE. Living-donor liver transplantation in adults. Langenbecks Arch Surg 1999;384:536-543.

6. Gridelli B, Spada M, Petz W, Bertani A, Lucianetti A, Colledan M, Altobelli M, Alberti D, Guizzetti M, Riva S, Melzi ML, Stroppa P, Torre G. Split-liver transplantation eliminates the need for livingdonor liver transplantation in children with end-stage cholestatic liver disease. Transplantation 2003;75:1197-1203.

7. Trotter JF, Wachs M, Everson GT, Kam I. Adult-to-adult transplantation of the right hepatic lobe from a living donor. N Engl J Med 2002;346:1074-1082.

8. Raia S, Nery JR, Mies S. Liver transplantation from live donors. Lancet 1989;2:497.

9. Strong RW, Lynch SV, Ong TH, Matsunami H, Koido Y, Balderson GA. Successful liver transplantation from a living donor to her son. N Engl J Med 1990;322:1505-1507.

10. Otte JB, de Ville DG, Reding R, Van Obbergh L, Veyckemans F, Carlier MA, De Kock M, Clement DC, Clapuyt P, Sokal E, Lerut J, Delbeke I, Dierick V, Janssen M, Rosati R, Libert F. Pediatric liver transplantation: from the full-size liver graft to reduced, split, and living related liver transplantation. Pediatr Surg Int 1998;13: 308-318.

11. Pichlmayr R, Ringe B, Gubernatis G, Hauss J, Bunzendahl H. Transplantation einer Spenderleber auf zwei Empfanger (Splitting-Transplantation) - eine neue Methode in der Weiterentwicklung der Lebersegmenttransplantation. Langenbecks Arch Chir 1988;373:127-130.

12. Rogiers X, Malago M, Gawad K, Jauch KW, Olausson M, Knoefel WT, Gundlach M, Bassas A, Fischer L, Sterneck M, Burdelski M, Broelsch CE. In situ splitting of cadaveric livers. The ultimate expansion of a limited donor pool. Ann Surg 1996;224:331-339.

13. Rela M, Heaton ND. Split-liver transplantation. Br J Surg 1998; 85:881-883

14. Rogiers X, Malago M, Nollkemper D, Sterneck M, Burdelski M, Broelsch CE. The Hamburg liver transplant program. Clin Transpl 1997;183-190.

15. Urata K, Kawasaki S, Matsunami H, Hashikura $\mathrm{Y}$, Ikegami T, Ishizone S, Momose Y, Komiyama A, Makuuchi M. Calculation of child and adult standard liver volume for liver transplantation. Hepatology 1995;21:1317-1321.

16. Sugawara $\mathrm{Y}$, Makuuchi M, Takayama T, Imamura H, Dowaki S, Mizuta K, Kawarasaki H, Hashizume K. Small-for-size grafts in living-related liver transplantation. J Am Coll Surg 2001;192: 510-513.

17. Lo CM, Fan ST, Liu CL, Chan JK, Lam BK, Lau GK, Wei WI, Wong J. Minimum graft size for successful living donor liver transplantation. Transplantation 1999;68:1112-1116.

18. Higashiyama H, Yamaguchi T, Mori K, Nakano Y, Yokoyama T, Takeuchi T, Yamamoto N, Yamaoka Y, Tanaka K, Kumada K. Graft size assessment by preoperative computed tomography in living related partial liver transplantation. Br J Surg 1993;80: 489-492.

19. Kiuchi T, Kasahara M, Uryuhara K, Inomata $\mathrm{Y}$, Uemoto S, Asonuma K, Egawa H, Fujita S, Hayashi M, Tanaka K. Impact of graft size mismatching on graft prognosis in liver transplantation from living donors. Transplantation 1999;67:321-327.

20. Lemasters JJ, Bunzendahl H, Thurman RG. Preservation of the liver. In: Maddrey WC, Schiff ER, Sorrell MF, eds. Transplantation of the liver. 3rd ed. Philadelphia: Lippincott Williams \& Wilkins, 2001:251-273.
21. Santori G, Andorno E, Fontana I, Cottalasso D, Valente U. Effects of ischemia-reperfusion on hepatic glutathione and plasmatic markers of graft function during in situ split-liver transplantation in adult recipients. Dig Dis Sci 2000;45:1981-1987.

22. Zhao BL, Li XJ, He RG, Cheng SJ, Xin WJ. Scavenging effect of extracts of green tea and natural antioxidants on active oxygen radicals. Cell Biophys 1989;14:175-185.

23. Slater TF. Free radical scavengers. In: Conn HO, ed. (+)-Cyanidanol-3 in diseases of the liver: international workshop. Volume 1. Crans-Montana, Switzerland: Academic Press Inc, 1981:11-15.

24. Zhong Z, Froh M, Connor HD, Li X, Conzelmann LO, Mason RP, Lemasters JJ, Thurman RG. Prevention of hepatic ischemia-reperfusion injury by green tea extract. Am J Physiol Gastrointest Liver Physiol 2002;283:G957-G964.

25. Zhong Z, Connor HD, Froh M, Lind H, Bunzendahl H, Mason RP, Thurman RG, Lemasters JJ. Polyphenols from Camellia sinenesis prevent primary graft failure after transplantation of ethanolinduced fatty livers from rats. Free Radic Biol Med 2004;36: 1248-1258.

26. Omura T, Ascher NL, Emond JC. Fifty-percent partial liver transplantation in the rat. Transplantation 1996;62:292-293.

27. Troisi R, Cammu G, Militerno G, De Baerdemaeker L, Decruyenaere J, Hoste E, Smeets P, Colle I, Van Vlierberghe H, Petrovic M, Voet D, Mortier E, Hesse UJ, de Hemptinne B. Modulation of portal graft inflow: a necessity in adult living-donor liver transplantation? Ann Surg 2003;237:429-436.

28. Kim JS, Broering DC, Tustas RY, Fischer L, Ganschow R, Burdelski M, Rogiers X. Split liver transplantation: past, present and future. Pediatr Transplant 2004;8:644-648.

29. Duling DR. Simulation on multiple isotropic spin-trap EPR spectra. J Magn Reson B 1994;104:105-110.

30. Diehl KH, Hull R, Morton D, Pfister R, Rabemampianina Y, Smith $\mathrm{D}$, Vidal JM, van de Vorstenbosch C. A good practice guide to the administration of substances and removal of blood, including routes and volumes. J Appl Toxicol 2001;21:15-23.

31. Ferrali M, Fulceri R, Benedetti A, Comporti M. Effects of carbonyl compounds (4-hydroxyalkenals) originating from the peroxidation of liver microsomal lipids on various microsomal enzyme activities of the liver. Res Commun Chem Pathol Pharmacol 1980;30: 99-112.

32. Chamulitrat W, Jordan SJ, Mason RP. Fatty acid radical formation in rats administered oxidized fatty acids: in vivo spin trapping investigation. Arch Biochem Biophys 1992;299:361-367.

33. Zhong Z, Connor H, Mason RP, Qu W, Stachlewitz RF, Gao W, Lemasters JJ, Thurman RG. Destruction of Kupffer cells increases survival and reduces graft injury after transplantation of fatty livers from ethanol-treated rats. Liver Transplant Surg 1996; 2:383-387.

34. Sugawara $\mathrm{Y}$, Makuuchi M. Technical advances in living-related liver transplantation. J Hepatobiliary Pancreat Surg 1999;6:245253.

35. Popper H, Paronetto F, Barka T. PAS-positive structures of nonglycogenic character in normal and abnormal liver. Arch Pathol 1960;70:300-312.

36. Doniach I, Weinbren K. The development of inclusion bodies in the cells of the rat's liver after partial hepatectomy. Br J Exp Pathol 1952;33:499-505.

37. Klatt EC, Koss MN, Young TS, Macauley L, Martin SE. Hepatic hyaline globules associated with passive congestion. Arch Pathol Lab Med 1988;112:510-513.

38. Shibayama Y, Hashimoto K, Nakata K. Role of sinusoidal pressure in the development of vacuolation in liver cells. J Pathol 1990;162:77-81.

39. Shibayama $Y$, Yahara M, Saitoh M, Nakata K. The pathogenesis of hyaline globules in liver cells after partial hepatectomy in rats. Exp Mol Pathol 1991;54:41-46. 
40. Connor HD, Gao W, Nukina S, Lemasters JJ, Mason RP, Thurman RG. Free radicals are involved in graft failure following orthotopic liver transplantation: an EPR spin trapping study. Transplantation 1992;54:199-204.

41. Currin RT, Toole JG, Thurman RG, Lemasters JJ. Evidence that Carolina rinse solution protects sinusoidal endothelial cells against reperfusion injury after cold ischemic storage of rat liver. Transplantation 1990;50:1076-1078.

42. Gao W, Takei Y, Marzi I, Lindert KA, Caldwell-Kenkel JC, Currin RT, Tanaka Y, Lemasters JJ, Thurman RG. Carolina rinse solution: a new strategy to increase survival time after orthotopic liver transplantation in the rat. Transplantation 1991;52:417-424.

43. Lehmann TG, Wheeler MD, Schoonhoven R, Bunzendahl H, Samulski RJ, Thurman RG. Delivery of $\mathrm{Cu} / \mathrm{Zn}$-superoxide dismutase genes with a viral vector minimizes liver injury and improves survival after liver transplantation in the rat. Transplantation 2000;69:1051-1057.

44. Lehmann TG, Wheeler MD, Schwabe RF, Connor HD, Schoonhoven R, Bunzendahl H, Brenner DA, Samulski RJ, Zhong Z, Thurman RG. Gene delivery of $\mathrm{Cu} / \mathrm{Zn}$-superoxide dismutase improves graft function after transplantation of fatty livers in the rat. Hepatology 2000;32:1255-1264.

45. Nohl H, Hegner D. Do mitochondria produce oxygen radicals in vivo? Eur J Biochem 1978;82:563-567.

46. Jaeschke H, Mitchell JR. Mitochondria and xanthine oxidase both generate reactive oxygen species in isolated perfused rat liver after hypoxic injury. Biochem Biophys Res Commun 1989;160: 140-147.

47. Boveris A, Chance B. The mitochondrial generation of hydrogen peroxide. General properties and effect of hyperbaric oxygen. Biochem J 1973;134:707-716.

48. Liu P, McGuire GM, Fisher MA, Farhood A, Smith CW, Jaeschke H. Activation of Kupffer cells and neutrophils for reactive oxygen formation is responsible for endotoxin-enhanced liver injury after hepatic ischemia. Shock 1995;3:56-62.

49. Decker K. Biologically active products of stimulated liver macrophages (Kupffer cells). Eur J Biochem 1990;192:245-261.

50. Stadler J, Bentz BG, Harbrecht BG, Di Silvio M, Curran RD, Billiar TR, Hoffman RA, Simmons RL. Tumor necrosis factor alpha inhibits hepatocyte mitochondrial respiration. Ann Surg 1992;216: 539-546.

51. McNally JS, Davis ME, Giddens DP, Saha A, Hwang J, Dikalov S, Jo $\mathrm{H}$, Harrison DG. Role of xanthine oxidoreductase and $\mathrm{NAD}(\mathrm{P}) \mathrm{H}$ oxidase in endothelial superoxide production in response to oscillatory shear stress. Am J Physiol Heart Circ Physiol 2003;285: $\mathrm{H} 2290-\mathrm{H} 2297$.

52. Schemmer $P$, Bunzendahl H, Raleigh JA, Thurman RG. Graft survival is improved by hepatic denervation before organ harvesting. Transplantation 1999;67:1301-1307.

53. Schemmer P, Schoonhoven R, Swenberg JA, Bunzendahl H, Thurman RG. Gentle in situ liver manipulation during organ harvest decreases survival after rat liver transplantation: role of Kupffer cells. Transplantation 1997;65:1015-1020.

54. Schemmer P, Connor HD, Arteel GE, Raleigh JA, Bunzendahl H, Mason RP, Thurman RG. Reperfusion injury in livers due to gentle in situ organ manipulation during harvest involves hypoxia and free radicals. J Pharmacol Exp Ther 1999;290:235-240.

Received May 21, 2004. Accepted May 4, 2005.

Address requests for reprints to: Zhi Zhong, MD, PhD, Department of Cell and Developmental Biology, CB\# 7090, University of North Carolina at Chapel Hill, Chapel Hill, North Carolina 27599. e-mail: zzhong@ med.unc.edu; fax: (919) 966-7197.

Supported in part by Grants K01 DK62089, DK37034, and P30 DK34987 from the National Institutes of Health. 